\title{
Have wild oats in Canterbury become resistant to herbicides?
}

\author{
K.C. Harrington ${ }^{1}$ and R.J. Chynoweth ${ }^{2}$ \\ ${ }^{1}$ Massey University, Private Bag 11222, Palmerston North 4442, New Zealand \\ ${ }^{2}$ Foundation for Arable Research, PO Box 23133, Templeton 8042, New Zealand \\ Corresponding author: K.C.Harrington@massey.ac.nz
}

To investigate rumours that herbicide resistance has developed in wild oats (Avena fatua), seeds of this species were collected from eight arable farms (either one or two populations per farm) in Canterbury from which possible resistance to either fenoxaprop-P-ethyl or haloxyfop had been reported. Seeds were also obtained from two properties where no resistance was thought to exist. Seeds from these 14 populations were germinated using dormancy-breaking techniques and established individually in pots within a glasshouse in October 2013. When seedlings were 4 weeks old, they were sprayed with the recommended rate of fenoxaprop-P-ethyl, haloxyfop or flamprop-M-isopropyl. None of the populations were controlled adequately by flamprop-M-isopropyl because insufficient competition was exerted on the seedlings following application as required to make this herbicide work well. One of the 14 populations was poorly controlled by all three herbicides, suggesting it has developed resistance to these herbicides. The remaining populations were adequately controlled by fenoxaprop-P-ethyl and haloxyfop. However, seedlings of one of these susceptible populations were not treated with fenoxapropP-ethyl until they were 6 weeks old and these were not controlled, showing the importance of applying this herbicide early enough while seedlings are still susceptible.

\section{A glyphosate-resistant perennial ryegrass population is also resistant to amitrole}

\author{
H. Ghanizadeh ${ }^{1}$, K.C. Harrington ${ }^{1}$, T.K. James ${ }^{2}$ and D.J. Woolley ${ }^{1}$ \\ ${ }^{1}$ Institute of Agriculture and Environment, Massey University, PB 11-222, Palmerston North 4442, \\ New Zealand \\ ${ }^{2}$ AgResearch, Ruakura Research Centre, PB 3123, Hamilton 3240, New Zealand \\ Corresponding author: K.Harrington@massey.ac.nz
}

A dose-response experiment was conducted on a previously confirmed glyphosate resistant perennial ryegrass (Lolium perenne) population from a Marlborough vineyard to examine if it is also resistant to amitrole after an initial experiment suggested amitrole is less effective on this population. The plants of two populations of perennial ryegrass, Population O (glyphosate resistant) and Population SP (glyphosate susceptible) were multiplied up by splitting out tillers and planting them into pots. The plants were sprayed with rates of amitrole from 0 to $9600 \mathrm{~g}$ ai/ha and each treatment consisted of five replicates (one plant per replicate). The dry weight of plant material was measured 8 weeks after herbicide application. The data were fitted to a three parameter logistic model and the herbicide rate giving 50\% reduction in growth (GR50) was calculated. The GR50 value of Population SP for amitrole was $523 \mathrm{~g}$ ai/ha whereas the GR50 for Population $\mathrm{O}$ was found to be 13.1 times greater. This is the first confirmed case of amitrole resistance evolving within New Zealand and further work is currently underway to study this resistance. 